\title{
Bioatividade de extratos aquosos de plantas medicinais em sementes de feijão-fava
}

NOBRE, D.A.C1*; MENDES, R,B2; PORTO, B.B.A2; AZEVEDO, D.M.Q2; BRANDÃO JUNIOR, D.S 2

Universidade Federal de Viçosa - UFV. Av. P.H. Ralfs, s/n, Centro, CEP 36571-000, Viçosa-MG. IInstituto de Ciências Agrárias da Universidade Federal de Minas Gerais- ICA/UFMG, Av. Universitária, 1000 - Universitário, CEP 39.404-006, Montes Claros-MG. *danubia_nobre@yahoo.com.br

RESUMO: O objetivo do presente estudo foi avaliar a bioatividade de extratos aquosos de plantas medicinais em sementes de Phaseolus lunatus L. (feijão-fava) via comportamento fisiológico e fitossanitário. Foram utilizadas sementes de feijão-fava da variedade Anduzinha tratadas com seis extratos aquosos de plantas medicinais a 5\% (Ocimun gratissimum, Plectranthus neachilus, Vernonia condensata, Cymbopogom citratus, Equisetum sp., e Piper aduncum L.), juntamente com a testemunha (água destilada). A bioatividade foi determinada pelo comportamento fisiológico e sanitário avaliados por meio dos testes de germinação, primeira contagem de germinação, índice de velocidade de germinação, comprimento de raiz na primeira e última contagem, e teste de sanidade. Realizou-se a análise de variância e teste Tukey a $5 \%$ de probabilidade. O extrato aquoso de cavalinha (Equisetum $s p$.) promoveu a melhor qualidade fisiológica das sementes de feijão-fava. Houve maior incidência de fungos nas sementes de feijão-fava que receberam o extrato de boldinho (Plectranthus neachilus).

Palvras-chave: Phaseolus lunatus L., plantas medicinais, germinação, vigor, alelopatia.

\begin{abstract}
Behavioral and physiological health of lima bean seeds subjected to aqueous extract of medicinal plants. The aim of this study was to evaluate the bioactivitt of medicinal lants aqueous extracts in Phaseolus lunatus L. (lima bean) s via through physiological and behavioral health. We the llima bean seeds of the variety Anduzinha ins of medicinal lants aqueous extracs ato 5\% (Ocimun gratissimum, Plectranthus neachilus, Vernonia condensata, Cymbopogom citratus, Equisetum sp. and Piper aduncum L.) together with the control (distilled water). The bioactivity was determined by physiological and sanitary qutyies reviews through germination, first counting of germination, speed of germination, root length in the first and last counting, and sanity check. We carried out the analysis of variance and the Tukey test at $5 \%$ probability. The aqueous extract of Equisetum sp. promoted beseed physiological quality of the lima bean seed. There was a higher incidence of fungs of lima bean sract that received the extract of Plectranthus neacilus).
\end{abstract}

Keywords: Phaseolus lunatus L., medicinal plants, germination, vigor, allelopathy.

\section{INTRODUÇÃO}

O sistema de cultivo misto ou intercalado tem despertado a atenção, principalmente pela riqueza das interações ecológicas, do arranjo e manejo da cultura, além de sua importância econômica. Sobre o consórcio com plantas medicinais, estudos realizados apresentam resultados significativos, visto que, algumas espécies possuem característica de atrair ou repelir insetos, sendo atrativas e nutritivas para parasitoides, melhoram o crescimento e o sabor de outras plantas e podem ser cultivadas em ambiente parcialmente sombreado (Maia et al. 2008; Moraes et al. 2008; Song et al. 2010).

Tendo em vista a importância da consorciação e a ampla utilização das plantas medicinais, estas podem ser implantadas juntamente com outras cultras;, no entanto, para leguminosas os estudos ainda são escassos.

Diante do exposto, o feijão-fava (Phaseolus lunatus L.), leguminosa utilizada para fornecer proteína vegetal na alimentação humana e animal, fonte de adubação verde ou cultura de cobertura para proteção do solo (Vieira 1992, Alcântara 1998, Pegado et al. 2008), apresenta-se como interessante opção de proddçãoe, pode ser implantada com outras culturas, tais como as plantas medicinais, já que estas são fornecedoras de óleos essenciais, largamente utilizadas em temperos, aromatizantes de licores, e de perfumes finos e, algumas espécies, 
apresentam ainda propriedades que permitem o desenvolvimento de defensivos agrícolas naturais e medicamentos (Lorenzi \& Matos, 2002; Gaia et al., 2011).

Estudos apontam o efeito da alelopatia de algumas espécies medicinais sobre sementes de espécies cultivadas e invasoras (Magiero et al., 2009; Rickli et al., 2011), tendo esta, efeito prejudicial ou benéfico entre as plantas at meio de substâncias químicas, chamadas de aleloquímicos, lançadas no meio. As substâncias alelopáticas podem interferir na germinação de sementes e/ou estabelecimento e desenvolvimento de indivíduos vegetais próximos (Ferreira, 2004; Gatti et al., 2007).

Para Chiapusio et al. (1997), a germinação de sementes é um bom indicador das reais potencialidades de um dado aleloquímico. Dessa forma, grande parte dos aleloquímicos atua no estresse oxidativo, produzindo oxigênio reativo, que atua diretamente ou como sinalizador para os processos de degradação celular, impedindo assim a germinação e o desenvolvimento inicial, bem como processos fisiológicos vitais às plantas (Almeida et al., 2008). No entanto, existe ainda a necessidade de se detectar essas substâncias e também a melhor metodologia para obtenção dos extratos, de modo a otimizar o efeito das propriedades medicinais (Venturoso et al., 20010). Neste sentido, considerando que é necessária a produção de alimentos e a interação ecológica entre as diferentes culturas, o objetivo do estudo foi avaliar a bioatividade de extrato aquoso de plantas medicinais em sementes de feijão-fava via comportamento fisiológico e sanitário.

\section{MATERIAL E MÉTODOS}

As sementes de fava, variedade Anduzinha, utilizadas neste estudo foram obtidas de uma área de plantio localizada no município de Montes Claros, MG; situada à latitude de $16^{\circ} 44>06 »$ W, longitude de $43^{\circ} 51$ > 42 » $\mathrm{W}$ e altitude de 648 metros.

O experimento foi realizado no Laboratório de Sementes do Instituto de Ciências Agrárias da Universidade Federal de Minas Gerais (ICA-UFMG). Os tratamentos foram constituídos de testemunha (água destilada) e extratos aquosos das espécies medicsendo: alfavaca-cravo (Ocimun gratissimum), boldinho (Plectranthus neachilus), boldo-baiano (Vernonia condensata), capim-limão (Cymbopogom citratus), cavalinha (Equisetum sp.) e pimenta de macaco (Piper aduncum L.), coletadas no horto medicinal da Universidade Federal de Minas Gerais.

Para o prepro dos extratos, as folhas foram coletela manhã,foram pesadas em balnça de precisão, e imersas emlada obtendo uma na proporção de $30 \mathrm{~g}$ de folhas frescas para 600
$\mathrm{mL}$ de ratura ambiente, sendo trituradas em liquidificador por 1 minuto a temperatura ambietos, em seguida, foram filtrados três vezes consecutivas em peneira de malha fina e em seguida obtevese a concentração de $5 \%$ para cada extrato, considerando a concentração inicial de 100\%.

O comportamento fisiológico foi determinado pelos testes de germinação e vigor. Os testes foram realizados em conjunto, sendo utilizadas quatro repetições de 50 sementes por tratamento.

As sementes inicialmente foram tratadas com hipoclorito de sódio $2 \%$ durante 2 minutos, evitando a interferência de microrganismos no substrato. Após a secagem natural das sementes, estas foram colocadas no substrato papel germitest, previamente umedecidos com os diferentes extratos aquosos, em quantidade equivalente a 2,5 vezes o peso do papel e água destilada apenas para o controle. Em seguida, foram transferidas para câmara B.O.D., mantidas a temperatura de $25^{\circ} \mathrm{C}$ e fotoperíodo de 12 horas. As avaliações foram realizadas no quinto e nono dia após a montagem do teste. Os resultados foram obtidos pela contagem de sementes germinadas normais e anormais (Brasil, 2009). Todos os resultados foram convertidos em porcentagem.

Juntamente com o teste de germinação realizou-se o teste de primeira contagem de germinação (vigor), determinado após cinco dias da montagem do teste. Determinou-se ainda o vigor das plâs, atraés dapelas medidas das raízes principais de dez plântulas normais de cada repetição dos diferntes tratamentos;, o mesmo foi realizado para a contagem final. As medidas foram realizadas com auxílio de uma régua graduada em centímetros, sendo os resultados expressos em centímetros por plântula.

As avaliações para o índice de velocidade de germinação (IVG) foram realizadas durante 9 dias, anotado-se diariamente, no mesmo horário, o número de sementes que haviam emitido $0,5 \mathrm{~cm}$ da radícula (raiz principal). Ao final desse teste de vigor, com os dados diários do número de sementes germinadas, calculou-se o IVG, empregando-se a fórmula proposta por Maguire (1962).

$O$ teste de sanidade foi realizado pelo método do papel mata-borrão em caixa gerbox, com uma camada fina de BDA. Os tratamentos foram compostos pelos diferentes extratos aquosos, onde as sementes ficaram submersas por 10 minutos. Em seguida, foram divididas em quatro repetições de 25 sementes cada. As caixas gerbox foram esterilizadas com álcool etílico $70 \%$, e o papel filtro e BDA autoclavado por meia ra. Utilizou-se a capela de fluxo laminar para transferir as sementes para as caixas, que continham duas folhas de papel filtro umedecido com o meio de cultura BDA. O teste 
foi conduzido com tratamento cberamtratamentos. As caixas com as sementes foram colocadas em congelador por 24 horas a teperatura de $10^{\circ} \mathrm{C}$, para impedir a germinação. Em seguida, foram transferidas para a B.O.D. onde permaneceram por sete dias, completando assim o período de oito dias de incubação. Após este período, as sementes foram analisadas em lupa esterioscópica e microscópio óptico para determinação e quantificação dos fungos (MACHADO, 1988).

O delineamento experimental utilizado foi inteiramente casualizado e os dados em porcentagem foram transformados em arco seno $\sqrt{\times / 100}$, sendo submetidos à análise de variância, e as características em nível de 5\% foram submetidatambém em nível de à $5 \%$ de probabilidade.

\section{RESULTADOS E DISCUSSÃO}

Conforme a Tabela 1, os resultados médios de germinação e vigor (primeira contagem do teste de germinação, plântulas anormais e comprimento de raízes) de sementes de feijão-fava apresentaram efeitos significativos a $5 \%$ de probabilidade e diferiram pelo teste de média, ao compararem-se os diferentes tratamentos alelopáticos, enquanto que, o índice de velocidade de germinação não exibiu diferença.

A germinação das sementes de feijão-fava, quando tratadas com extrato aquoso de cavalinha e pimenta de macaco apresentaram maiores médias de germinação, e não diferiram estatisticamente entre si. Porém, apenas o extrato de cavalinha diferiu $(p<0,05)$ dos demais tratamentos e da testemunha (Tabela 1).

Ferreira et al. (2010), revelaram que diferentes concentrações do extrato de folhas jovens de sabiá (Mimosa caesalpiniaefolia Benth.) não apresentaram efeito prejudicial a germinação das sementes de feijão-fava. O mesmo foi observado no presente estudo, pois em comparação com a testemunha, o extrato de cavalinha favoreceu a porcentagem de germinação das sementes.

O efeito alelopático, muitas vezes, não se dá pela germinabilidade, mas sobre a velocidade de germinação, ou seja, sobre o vigor das sementes (Ferreira et al., 2004). Neste sentido, quanto ao vigor, avaliado pelo teste de primeira contagem de germinação (Tabela 1), observou-se maiores médias para as sementes quando receberam o extrato de alfavaca-cravo, cavalinha, pimenta de macaco e a testemunha, que não diferiram entre si, mas, diferiram daquelas que receberam o extrato de capim-limão, sendo este tratamento o que exibiu as menores médias, porém, não diferiu dos extratos de boldo e de boldinho.

Conforme Iganci et al. (2006), extratos das diferentes espécies de boldo influenciaram na germinaçãoe no desenvolvimento inicial das plântulas de cebola, além disto, a cebola mostrou ser um biomonitor sensível a estes extratos. Na presente pesquisa, o feijão-fava apresentou sensibilidade aos extratos de boldo apenas ao se avaliar o vigor das sementes.

Dalmolin et al. (2012) ao avaliarem extratos aquosos obtidos de folhas de capim limão observaram que houve alteração no padrão de germinação de sementes de picão-preto (Bidens pilosa L.); para o presente estudo, em sementes de feijão-fava, a germinação não apresentou reduções devida ao extrato de capim limão.

Sabendo-se que as plântulas anormais podem ser um indicio de reação alelopatica,

TABELA 1. Efeitos fisiológicos de extratos de plantas medicinais sobre germinação (G), primeira contagem (PC), plântulas anormais (PA), índice de velocidade de germinação (IVG), comprimento de raízes na primeira contagem (CRPC) e comprimento de raízes na contagem final (CRCF) de plântulas de feijão-fava.

\begin{tabular}{lllllll}
\hline Tratamentos & $\mathrm{G}$ & $\mathrm{PC}$ & $\mathrm{PA}$ & $\mathrm{IVG}$ & $\begin{array}{l}\text { CRPC } \\
(\mathrm{cm})\end{array}$ & $\begin{array}{l}\text { CRCF } \\
(\mathrm{cm})\end{array}$ \\
\hline Alfavaca-cravo & $72,0 \mathrm{~b}$ & $55,5 \mathrm{ab}$ & $10,2 \mathrm{a}$ & $16,5 \mathrm{a}$ & $4,2 \mathrm{c}$ & $3,8 \mathrm{c}$ \\
Boldinho & $71,0 \mathrm{~b}$ & $40,0 \mathrm{bcd}$ & $12,8 \mathrm{a}$ & $16,4 \mathrm{a}$ & $2,6 \mathrm{c}$ & $2,8 \mathrm{c}$ \\
Boldo & $65,0 \mathrm{~b}$ & $36,5 \mathrm{~cd}$ & $16,5 \mathrm{a}$ & $16,5 \mathrm{a}$ & $3,0 \mathrm{c}$ & $3,2 \mathrm{c}$ \\
Capim-limão & $64,0 \mathrm{~b}$ & $25,0 \mathrm{~d}$ & $16,2 \mathrm{a}$ & $16,3 \mathrm{a}$ & $3,2 \mathrm{c}$ & $3,2 \mathrm{c}$ \\
Cavalinha & $89,0 \mathrm{a}$ & $67,0 \mathrm{a}$ & $3,2 \mathrm{~b}$ & $16,2 \mathrm{a}$ & $8,2 \mathrm{ab}$ & $7,6 \mathrm{ab}$ \\
Pimenta de macaco & $77,0 \mathrm{ab}$ & $54,0 \mathrm{abc}$ & $9,7 \mathrm{a}$ & $16,2 \mathrm{a}$ & $10,5 \mathrm{a}$ & $11,10 \mathrm{a}$ \\
Testemunha & $74,0 \mathrm{~b}$ & $59,5 \mathrm{a}$ & $12,3 \mathrm{a}$ & $16,5 \mathrm{a}$ & $10,3 \mathrm{a}$ & $8,8 \mathrm{a}$ \\
\hline C.V. (\%) & 7,47 & 9,46 & 15,25 & 1,24 & 23,28 & 25,06 \\
\hline
\end{tabular}

Médias seguidas de mesma letra na coluna, não diferem entre si pelo teste Tukey a $5 \%$.

Rev. Bras. PI. Med., Campinas, v.16, n.2, supl. I, p.467-472, 2014. 
Barreiro et al. (2005) em estudos com o extrato de parte aérea de barbatimão (Stryphnodendron adstringens), observou que houve redução da formação de plântulas normais de pepino (Cucumis sativus). Assim, pode se observar no presente estudo, conforme apresentado na Tabela 1, que o extrato de cavalinha foi o único que exibiu as menores médias de plântulas anormais, diferindo dos demais. No entanto, é importante ressaltar que os demais extratos não diferiram da testemunha, assim, os extratos utilizados não promoveram efeitos prejudiciais.

Avaliando ainda o vigor das plântulas, realizou-se a medida (Tabela 1) de comprimento das raízes na primeira contagem, e observou-se que os maiores comprimentos foram expressos pelas plântulas que receberam extrato de cavalinha, pimenta de macaco e a testemunha, mas que não apresentaram efeito significativo entre si, porém, diferiram das demais.

Manoel et al. (2009), observaram o efeito alelopático no comprimento de raízes de tomate ao utilizarem extratos de folhas frescas e secas de barbatimão e pata-de-vaca (Bauhinia forficata link), comprovando assim o efeito de extratos no desenvolvimento de plântulas.

Rosado et al. (2009), verificaram a redução do crescimento radicular em sementes de alface e melissa pelo uso de extratos aquosos de manjericão. Portanto, conforme apresentado na Tabela 1, os extratos aquosos de alfavaca-cravo, boldinho, boldo e capim-limão podem apresentar compostos capazes de reduzir o desenvolvimento das raízes de feijão fava.

Outro fator de fundamental importância é ação dos compostos medicinais sobre os fitopatogenos. A Tabela 2 apresenta os resultados médios de incidência de fungos nas sementes de feijão-fava após serem tratadas com extrato aquoso das plantas medicinais e hipoclorito de sódio $2 \%$.

Para o gênero Acremonium sp., foiobservado maior ocorrencia nassementes tratadas com extrato de boldo e boldinho, estas, diferiram apenas daquelas tratadas com hipoclórito de sódio, que apresentaram as menores médias; o gênero Alternaria sp. obteve maior incidência nas sementes que receberam o extrato de alfavacacravo, cavalinha e pimenta de macaco, estas não diferiram daquelas que receberam o extrato de boldo, porém, diferiram das demais.

Para o Aspergillus sp. a diferença significativa foi entre o hipoclorito de sódio e os demais. O gênero Cladosporium sp. apresentou elevada incidência apenas para as sementes que receberam o extrato aquoso de boldinho, diferindose dos demais extratos.

Os fungos do gênero Colletotrichum sp. exibiram maior incidência nas sementes tratadas com boldo e pimenta de macaco, diferindo das demais, apenas este foi observado nas sementes que receberam o tratamento com hipoclorito de sódio. Já o Curvularia sp. obteve maior incidência na presença de extratos de boldo, pimenta de macaco e boldinho; o gênero Fusarium sp. foi observado em maior porcentagem para os extratos de capim-limão, cavalinha, boldinho e a testemunha; enquanto que o gênero Nigrospora sp., foi observado apenas para aquelas sementes que receberam extrato aquoso de pimenta de macaco.

Silva et al. (2012) apresentaram extratos aquosos de plantas medicinais e aromáticas eficientes no controle de micélios de fungos do gênero Colletotrichum e Fusarium.

Conforme expresso na Tabela 2, a contaminação por alguns gêneros eam provenienes das sementes, já que, a testemunha também exibiu

TABELA 2. Resultados médios (\%) de incidência dos gêneros de fungos em sementes de feijão-fava sobre os extratos de plantas medicinais.

\begin{tabular}{lllllllll}
\hline \multirow{2}{*}{ Tratamentos } & \multicolumn{2}{l}{ Gêneros de Fungos } & \multicolumn{1}{l}{} \\
\cline { 2 - 8 } & Acr. & Alt. & Asp. & Cla. & Col. & Cur. & Fus. & Nig. \\
\hline Testemunha & $7,0 \mathrm{bc}$ & $0,0 \mathrm{c}$ & $71,0 \mathrm{a}$ & $9,0 \mathrm{~cd}$ & $31,0 \mathrm{ab}$ & $1,0 \mathrm{c}$ & $90,0 \mathrm{a}$ & $0,0 \mathrm{~b}$ \\
Hipoclórito & $0,0 \mathrm{c}$ & $0,0 \mathrm{c}$ & $0,0 \mathrm{~b}$ & $0,0 \mathrm{~d}$ & $3,0 \mathrm{~b}$ & $0,0 \mathrm{c}$ & $0,0 \mathrm{~d}$ & $0,0 \mathrm{~b}$ \\
Capim-limão & $1,0 \mathrm{bc}$ & $0,0 \mathrm{c}$ & $64,0 \mathrm{a}$ & $1,0 \mathrm{~d}$ & $3,0 \mathrm{~b}$ & $1,0 \mathrm{c}$ & $44,0 \mathrm{abc}$ & $0,0 \mathrm{~b}$ \\
Boldo & $32,0 \mathrm{ab}$ & $1,0 \mathrm{bc}$ & $38,0 \mathrm{a}$ & $18,0 \mathrm{bc}$ & $59,0 \mathrm{a}$ & $24,0 \mathrm{a}$ & $28,0 \mathrm{bc}$ & $0,0 \mathrm{~b}$ \\
Pimenta de macaco & $17,0 \mathrm{bc}$ & $7,0 \mathrm{ab}$ & $37,0 \mathrm{a}$ & $10,0 \mathrm{~cd}$ & $55,0 \mathrm{a}$ & $13,0 \mathrm{ab}$ & $33,0 \mathrm{bc}$ & $3,0 \mathrm{a}$ \\
Cavalinha & $13,0 \mathrm{bc}$ & $6,0 \mathrm{ab}$ & $51,0 \mathrm{a}$ & $38,0 \mathrm{~b}$ & $3,0 \mathrm{~b}$ & $1,0 \mathrm{c}$ & $70,0 \mathrm{a}$ & $0,0 \mathrm{~b}$ \\
Boldinho & $68,0 \mathrm{a}$ & $0,0 \mathrm{c}$ & $70,0 \mathrm{a}$ & $80,0 \mathrm{a}$ & $16,0 \mathrm{~b}$ & $8,0 \mathrm{abc}$ & $52,0 \mathrm{ab}$ & $0,0 \mathrm{~b}$ \\
Alfavaca-cravo & $12,0 \mathrm{bc}$ & $2,0 \mathrm{abc}$ & $42,0 \mathrm{a}$ & $7,0 \mathrm{~cd}$ & $28,0 \mathrm{ab}$ & $2,0 \mathrm{bc}$ & $18,0 \mathrm{~cd}$ & $0,0 \mathrm{~b}$ \\
\hline
\end{tabular}

Médias seguidas de mesma letra na coluna, não diferem entre si pelo teste Tukey a $5 \%$.

Acr.: Acremonium sp.; Alt.: Alternaria sp.; Asp.: Aspergillus sp.; Cla.: Cladosporium sp.; Col.: Colletotrichum sp.; Cur.: Curvularia sp.; Fus.:Fusarium sp.; Nig.: Nigrospora sp. 
alguns gêneros de fungo;, no entanto, o elevado índice de contaminação pode ainda ser explicado pelo fatoe os extratos não serem sanitizados antes da aplicação nas sementes, sendo possível que as próprias plantas medicinais já traziam os patógenos no momento da extração.

Kanieski et al. (2008) relataram que o extrato aquoso de espirradeira não foi eficiente para o controle de patógenos associados às sementes de canafístula, observando-se ainda que o mesmo incentivou o aparecimento de fungos. O mesmo foi observado no presente estudo para a utilização de alguns extratos.

Diante do exposto, ocorre bioatividade de extratos aquosos de plantas medicinais em sementes de feijão fava, sendo verificado que o extrato aquoso de cavalinha (Equisetum sp.) promoveu melhor qualidade fisiológica às sementes de feijão-fava e, houeá maior incidência de fungos nas sementes que receberam o extrato de boldinho (Plectranthus neachilus).

\section{AGRADECIMENTOS}

À UFMG, pelo apoio no desenvolvimento do presente estudo.

\section{REFERÊNCIA}

ALCÂNTARA, F.A. Adubação verde na recuperação da fertilidade de um solo degradado. 104f. Dissertação (mestrado em agronomia) - Universidade Federal de Lavras, Lavras-MG, 1998.

ALMEIDA, G.D.A.; ZUCOLOTO, M.; ZETUN, M.C.; COELHO, I.; SOBREIR, F.M. Estresse oxidativo em células vegetais mediante aleloquímicos. Revista Facultad Nacional de Agronomia, v.61, n.1, p.42374247, 2008.

BARREIRO, A.P.; DELACHIAVE, M.E.A.; SOUZA, F.S. Efeito alelopático de extratos de parte aérea de barbatimão [Stryphnodendron adstringens (Mart.) Coville] na germinação e desenvolvimento da plântula de pepino. Revista Brasileira de Plantas Medicinais, v.8, n.1, p.4-8, 2005.

BRASIL. Ministério da Agricultura, Pecuária e Abastecimento. Regras para análise de sementes. Secretaria de Defesa Agropecuária. Brasília: Mapa/ ACS. 2009. 399p.

CHIAPUSIO, G.; SÁNCHEZ, A. M.; REIGOSA, M. J.; GONZÁLEZ, L.; PELLISSIER, F. Do germination indices adequately reflect allelochemical effects on the germination process?. Journal of Chemical Ecology, v.23, n.11, p.2445-2453, 1997.

DALMOLIN, S.F.; PERSEL, C.; CRUZ-SILVA, C.T.A. Alelopatia de capim-limão e sálvia sobre a germinação de picão preto. Cultivando o Saber, v.5, n.3, p.176189, 2012.

FERREIRA, A. G. Interferência: competição e alelopatia. In: FERREIRA, A. G.; BORGHETTI, F. Germinação: do básico ao aplicado. Porto Alegre: Artmed, 2004. cap. 16 , p. 251-262.

FERREIRA, E.G.B.S.; MATOS, V.P.; SENA, L.H.M.; SALES, A.G.F.A. Efeito alelopático do extrato aquoso de sabiá na germinação de sementes de fava. Ciência Agronômica, v.41, n.3, p.463-467, 2010.

GAIA, J.M.D.; MOTA, M.G.C.; CONCEIÇÃO, C.C.C.; MAIA, J.G.S. Morphologic characterization of spiked pepper's germplasm. Horticultura Brasileira, v.29, n.2, p.162-167, 2011.

GATTI, A. B.; PEREZ, S. C. J. G. A.; FERREIRA, A. G. Avaliação da atividade alelopática de extratos aquosos de folhas de espécies de cerrado. Revista Brasileira de Biociências, v.5, n.2, p. 174-176, 2007.

IGANCI, J.R.V.; BOBROWSKI, V.L.; HEIDEN, G.; STEIN, V.C.; ROCHA, B.H.G. Efeito do extrato aquoso de diferentes espécies de boldo sobre a germinação e índice mitótico de Allium cepa L. Arquivos do Instituto Biológico, v.73, n.1, p.79-82, 2006.

KANIESKI, M.R.; CHASSOT, T.; MUNIZ, M.F.B. Efeitos do extracto aquoso de Nerium Oleander L. na germinação e na sanidade de sementes de Peltophorum dubium (Sprengel) Taubert. Revista de Ciências Agrárias, v.31, n.2, p.119-126, 2008.

LORENZI, H.; MATOS, F.J.A. Plantas medicinais no brasil: nativas e exóticas. nova odessa: instituto plantarum, 2002. 544p.

MAGIERO, E.C.; ASSMANN, J.M.; MARCHESE, J.A.; CAPELIN, D.; PALADINI M.V.; TREZZI, M.M. Efeito alelopático de Artemisia annua L. na germinação e desenvolvimento inicial de plântulas de alface (Lactuca sativa L.) e leiteiro (Euphorbia heterophylla L.). Revista Brasileira de Plantas Medicinais, v.11, n.3, p.317-324, 2009.

MACHADO, J. C. Patologia de sementes: fundamentos e aplicações. Brasília, DF: MEC/ESAL/FAEPE, 1988. $106 \mathrm{p}$.

MAGUIRE, J.D. Speed of germination-aid in selection and evaluation for seedlig emergence and vigor. Crop Science, v. 2, n. 1, p. 176-177, 1962.

MAIA, J.T.L.S.; GUILHERME, D.O.; PAULINO, M.A.O.; BARBOSA, F.S.; FERNANDES, R.C.; MAIO, M.M.; VALADARES, S.V.; COSTA, C. A.; MARTINS, E.R. Produção de alface e cenoura em cultivo solteiro e consorciado com manjericão e hortelã. Revista Brasileira de Agroecologia, v.3, n.1, p.58-64, 2008.

MANOEL, D.D.; DOICHE, C.F.R.; FERRARI, T.B.; FERREIRA, G. Atividade alelopática dos extratos fresco e seco de folhas de barbatimão (Stryphnodendron adstringens (Mart.) Coville) e pata-devaca (Bauhinia forficata link) sobre a germinação e desenvolvimento inicial de plântulas de tomate. Semina: Ciências Agrárias, v.30, n.1, p.63-70. 2009.

MORAES, A.A.; VIEIRA, M.D.; ZÁRATE, N.A.H.; TEIXEIRA, I.R.; RODRIGUES, E.T. Produção da capuchinha em cultivo solteiro e consorciado com os repolhos verde e roxo sob dois arranjos de plantas. Ciência e Agrotecnologia, v.32, n.4, p.1195-1202. 2008.

PEGADO, C.M.A., BARBOSA, L.J.N., MENDES, J.E.M.F., SOUTO, P.C. \& SOUTO, J.S.. Decomposição superficial e subsuperficial de folhas de fava (Phaseolus lunatus L.) na região do brejo da Paraíba, Brasil. Revista Caatinga, v.21, n.1, p. 218-223, 2008.

Rev. Bras. PI. Med., Campinas, v.16, n.2, supl. I, p.467-472, 2014. 
RICKLI, H.C.; FORTES, A.M.T.; SILVA, P.S.S.; PILATTI, D.M.; HUTT, D.R. Efeito aleopático de extrato aquoso de folhas de Azarirachia indica A. Juss. em alface, soja, milho, feijão e picão-preto. Semina: ciências agrárias, v.32, n.2, p.473-484, 2011.

ROSADO, L.D.; RODRIGUES, H.C.A.; PINTO, J.E.B.P.:; CUSTÓDIO, T.N.; PINTO, L.B.B.; BERTOLUCCI, S.K.V. S. Alelopatia do extrato aquoso e do óleo essencial de folhas do manjericão "Maria Bonita" na germinação de alface, tomate e melissa. Revista Brasileira de Plantas Medicinais, v.11, n.4, p.4228, 2009.

SILVA, J.L.; TEIXEIRA, R.N.V.; SANTOS, D.I.P.; PESSOA, J.O. Atividade antifúngica de extratos vegetais sobre o crescimento in vitro de fitopatógenos.
Revista Verde, v.7, n.1, p.80-86, 2012.

SONG, B.Z; WU, H.Y; KONG, Y.; ZHANG, J.; DU, Y.L.; $\mathrm{HU}$, J.H.; YAO, Y.C. Effects of intercropping with aromatic plants on the diversity and structure of an arthropod community in a pear orchard. Bio control, v.55, p. 741-751, 2010.

VENTUROSO, L.R.; BACCHI, L.M.A.; GAVASSONI, W.L.; PONTIM, B.C.A.; CONUS, L.A. Influência de diferentes metodologias de esterilização sobre a atividade antifúngica de extratos aquosos de plantas medicinais. Revista Brasileira de Plantas Medicinais, v.12, n.4, p.499-505, 2010.

VIEIRA, C. Leguminosas de grãos: importância econômica na agricultura e na alimentação humana. Informe Agropecuário, v.16, n.174, p.5-11, 1992. 